\title{
KUALITAS HIDUP PENDERITA INSOMNIA PADA MAHASISWA PASCASARJANA UNIVERSITAS HASANUDDIN
}

\section{QUALITY OF LIFE OF PATIENTS WITH INSOMNIA IN HASANUDDIN UNIVERSITY GRADUATE STUDENTS}

\author{
Muhammad Akbar Nurdin, ${ }^{1}$ A. Arsunan Arsin, ${ }^{2}$ Ridwan M. Thaha ${ }^{3}$ \\ ${ }^{1}$ Fakultas Kesehatan Masyarakat Universitas Hasanuddin \\ ${ }^{2}$ Bagian Epidemiologi Fakultas Kesehatan Masyarakat Universitas Hasanuddin \\ ${ }^{3}$ Bagian Promosi Kesehatan dan Ilmu Perilaku Fakultas Kesehatan Masyarakat Universitas \\ Hasanuddin
}

\author{
Alamat Korespondensi: Muhammad Akbar Nurdin, S.KM, Fakultas Kesehatan Masyarakat \\ Universitas Hasanuddin Makassar, \\ Email:nurdinakbar9@gmail.com,Telp:082187477718
}

\begin{abstract}
Abstrak
Insomnia adalah kelainan dalam tidur berupa kesulitan berulang untuk tidur atau mempertahankan tidur walaupun ada kesempatan untuk itu dan gejala tersebut biasanya diikuti gangguan fungsional saat bangun dan beraktivitas di siang hari. Sepertiga orang dewasa mengalami kesulitan memulai tidur dan mempertahankan tidur dalam setahun, dengan $17 \%$ diantaranya mengganggu kualitas hidup. Penelitian ini bertujuan untuk mengetahui faktor yang mempengaruhi kualitas hidup penderita insomnia pada Mahasiswa Pascasarjana Universitas Hasanuddin. Jenis penelitian yang digunakan rancangan cross sectional study. Sampel penelitian menggunakan metode exhaustive sampling sebanyak 215 responden yang menderita insomnia. Data dianalisis menggunakan analisis jalur. Hasil analisis bivariat menunjukkan ada pengaruh antara perilaku merokok terhadap tingkat insomnia dengan nilai koefisien 0.425 dan terhadap kualitas hidup dengan nilai koefisien -0.205 . Ada pengaruh konsumsi kafein terhadap tingkat insomnia dengan nilai koefisien 0.392 dan terhadap kualitas hidup dengan nilai koefisien -0.142. Ada pengaruh aktivitas fisik terhadap tingkat insomnia dengan nilai koefisien 0.192 dan terhadap kualitas hidup dengan nilai koefisien -0.409 . Hasil analisis multivariat efek tidak langsung perilaku merokok terhadap kualitas hidup melalui tingkat insomnia yaitu -0.174. Efek tidak langsung konsumsi kafein terhadap kualitas hidup melalui tingkat insomnia adalah -0.160. Efek tidak langsung aktivitas fisik terhadap kualitas hidup melalui tingkat insomnia adalah -0.079 .
\end{abstract}

Kata kunci: Insomnia, perilaku merokok, konsumsi kafein, aktivitas fisik, kualitas hidup

\begin{abstract}
Insomnia is a sleep disorder in the form of a recurring difficulty to sleep or maintaining sleep although there are opportunities for it and the symptoms are typically followed by functional impairment while awake and active in the daytime. One-third of adults experience difficulty in initiating sleep and maintaining sleep in a year, with $17 \%$ of them interfere with quality of life. This study aimed to determine the factors that affect the quality of life of patients with insomnia at Hasanuddin University Post Graduate Students. This research type used cross sectional study. The research sample used the method of exhaustive sampling of 215 respondents who suffer from insomnia. Data were analyzed using path analysis. The results of the bivariate analysis showed that no effect between smoking behavior of the level of insomnia with the coefficient of 0.425 and the quality of life with coefficient -0.205. There was an effect of caffeine consumption on the level of insomnia with coefficient 0.392 and the quality of life with coefficient -0.142. There was the influence of physical activity on the level of insomnia with coefficient 0.192 and the quality of life with coefficient -0.409. Multivariate analysis indirect effects of smoking behavior towards the quality of life through the level of insomnia that was -0.174. Indirect effects of caffeine consumption on quality of life through insomnia level was -0.160. Indirect effects of physical activity on quality of life through insomnia level was -0.079 .
\end{abstract}

Keywords: Insomnia, Smoking, Caffeine Consumption, Physical Activity, Quality Of Life 


\section{PENDAHULUAN}

Insomnia merupakan suatu kondisi yang dicirikan dengan adanya gangguan dalam jumlah, kualitas atau waktu tidur pada seorang individu. Gangguan tidur dapat mengganggu pertumbuhan fisik, emosional, kognitif, dan sosial seorang dewasa. Fakta tersebut menunjukkan besarnya kemungkinan masalah akademis, emosional, kesehatan, dan perilaku pada dewasa dapat dicegah atau diperbaiki secara signifikan melalui intervensi yang memperbaiki kualitas dan kuantitas tidur (LeBourgeois dkk., 2005). Gangguan pola tidur adalah suatu kondisi dimana seseorang mengalami resiko perubahan jumlah dan kualitas pola istirahat yang menyebabkan ketidaknyamanan. Klasifikasi gangguan tidur menurut International Classification of Sleep Disorder yaitu dissomnia, parasomnia, gangguan tidur berhubungan dengan gangguan kesehatan atau psikiatri, gangguan tidur yang tidak terklasifikasi (Japardi I, 2002)

Menurut NSF (National Sleep Foundation), gangguan tidur dapat menimbulkan beberapa efek pada manusia. Ketika kurang tidur seseorangakan berpikir dan bekerja lebih lambat, membuat banyak kesalahan, dan sulit untuk mengingat sesuatu. Hal ini mengakibatkan penurunan produktivitas kerja dan dapat menyebabkan kecelakaan. Efek lainnya pada pekerja yaitu pekerja menjadi lebih cepat marah, tidak sabar, gelisah dan depresi. Masalah ini dapat menggaggu pekerjaan dan hubungan keluarga, serta mengurangi aktivitas sosial. Kurang tidur pada pekerja merupakan penyebab utama terjadinya penurunan produktivitas, ketidakhadiran pekerja (absentisme), dan kecelakaan di tempat kerja. Di Indonesia, pada tahun 2010 terdapat $11,7 \%$ penduduk mengalami insomnia. Insomnia umumnya merupakan kondisi sementara atau jangka pendek. Dalam beberapa kasus, insomnia dapat menjadi kronis. Hal ini sering disebut sebagai gangguan penyesuaian tidur karena paling sering terjadi dalam konteks situasional depresi akut, seperti pekerjaan baru atau menjelang ujian. Insomnia ini biasanya hilang ketika depresior hilang atau individu telah beradaptasi dengan depresior. Namun, insomnia sementara sering berulang ketika tegangan baru atau serupa muncul dalam kehidupan pasien (Zeidler M, 2011)

Salah satu faktor yang akan dipengaruhi oleh insomnia adalah kualitas hidup. Kualitas hidup bisa dipandang dari segi subjektif dan objektif. Segi subjektif merupakan perasaan enak dan puas atas segala sesuatu secara umum, sedangkan secara objektif adalah pemenuhan tuntutan kesejahteraan materi, status sosial dan kesempurnaan fisik secara sosial budaya. Menurut Cella penilaian kualitas hidup penderita insomnia dapat dilihat pada aspek kesehatan fisik, kesehatan mental, fungsi sosial, fungsi peran dan perasaan sejahtera (Fatayi, 2008). Penelitian yang dilakukan oleh Annahri di Universitas Lambung Mangkurat Banjarmasin menunjukkan bahwa adahubungan antara perilaku merokok dengan angka kejadian insomnia (Annahri dkk., 2013). Hal ini sejalan dengan hasil penelitian yang pernah diakukan oleh Yocki menunjukkan bahwa ada hubungan antara perilaku merokok pada mahasiswa dengan kejadian insomnia (Yocki, 2007). Hal ini didukung juga dengan pernyataan Brook yang mengatakan bahwa nikotin yang terkandung dalam rokok merupakan salah satu pemicu terjadinya insomnia (Brook dkk., 2012). Selain itu, aktivitas fisik juga dapat menyebabkan insomnia. Hal tersebut sebagaimana dikemukakan oleh Gaung bahwa kurang berolahraga berdampak pikiran tidak tenang dan membuat seseorang depresi yang mengakibatkan insomnia (Gaung, 2009). Berdasarkan uraian diatas, maka penelitian ini bermaksud untuk menganalisis kualitas hidup penderita insomnia pada mahasiswa pascasarjana universitas hasanuddin tahun 2017. Penelitian ini bertujuan untuk mengetahui faktor yang mempengaruhi kualitas hidup penderita insomnia pada Mahasiswa Pascasarjana Universitas Hasanuddin. 


\section{BAHAN DAN METODE \\ Lokasi dan Rancangan Penelitian}

Penelitian ini dilakukan di Sekolah Pascasarjana Universitas Hasanuddin. Jenis penelitian ini adalah penelitian observational dengan pendekatan desain cross sectional study. Penelitian dilakukan pada 2 Mei - 22 September 2017.

\section{Populasi dan Sampel}

Populasi dalam penelitian ini yaitu mahasiswa pascasarjana strata 2 angkatan 2015 dan 2016, berjenis kelamin laki-laki dan menderita insomnia. Sampel penelitian sebanyak 215 orang menggunakan teknik exhaustive sampling.

\section{Analisis Data}

Analisis data dalam penelitian ini menggunakan analisis jalur (pathway analysis). Analisis jalur (Pathway Analisis) adalah sebuah metode untuk mempelajari pengaruh langsung dan tidak langsung dari variabel-variabel, yang pertama kali dikembangkan oleh Wright tahun 1921. Analisis jalur dapat digunakan untuk menganalisis hubungan sebab akibat antara satu variabel dengan variabel lainnya. Data primer diperoleh melalui kusioner penelitian dan wawancara dengan responden guna mendapatkan gambaran setiap variabel yang diteliti melalui wawancara langsung pada sampel terpilih. Data sekunder diperoleh melalui bidang akademik sekolah pascasarjana Universitas Hasanuddin guna mendapatkan nama dan jumlah mahasiswa strata 2 aktif tahun masuk 2015 dan 2016.

\section{HASIL}

\section{Karakteristik Responden}

Berdasarkan karakteristik responden menunjukkan bahwa kelompok umur 2635 tahun dengan proporsi tertinggi adalah yaitu 122 orang $(57.3 \%)$ dan proporsi terendah kelompok umur 36-45 tahun yaitu 17 orang $(8 \%)$. Berdasarkan tahun masuk, 2016 lebih banyak yaitu 111 orang (52.1\%) dibandingkan tahun masuk 2015 yaitu 102 orang $(47.5 \%)$. Berdasarkan suku didominasi oleh suku bugis sebanyak 96 orang $(45.1 \%)$ dan proporsi terendah yaitu sebanyak 49 orang (23\%) berasal dari suku lainnya, sementara proporsi untuk suku Makassar sebanyak 68 orang $(31.9 \%)$. Variabel proporsi sumber biaya kuliah, responden yang menggunakan biaya sendiri lebih banyak yaitu 127 orang (59.6\%) dibandingkan mahasiswa yang beasiswa yaitu 86 orang (40.4\%). Berdasarkan status pernikahan, responden dengan status menikah sebanyak 119 orang $(55.9 \%)$, belum menikah yaitu 94 orang (44.1\%). Berdasarkan fakultas, yang tertinggi adalah pada fakultas teknik yaitu 53 orang $(24.9 \%)$ dan proporsi terendah yaitu fakultas farmasi sebanyak 4 orang (1.9\%) (Tabel 1).

Tabel 1. Korelasi Antara Variabel Independen dengan Variabel Dependen

\begin{tabular}{ccc}
\hline Korelasi Variabel & Nilai $\mathbf{R}^{2}$ & Nilai r \\
\hline Perilaku Merokok $\rightarrow$ Tingkat Insomnia & 0.3343 & 11.66 \\
Perilaku Merokok $\rightarrow$ Kualitas Hidup & 0.4041 & -16.56 \\
Konsumsi Kafein $\rightarrow$ Tingkat Insomnia & 0.3636 & 1.088 \\
Konsumsi Kafein $\rightarrow$ Kualitas Hidup & 0.1434 & -0.894 \\
Aktivitas Fisik $\rightarrow$ Tingkat Insomnia & 0.4181 & 7.304 \\
Aktivitas Fisik $\rightarrow$ Kualitas Hidup & 0.3825 & -8.921 \\
Tingkat Insomnia $\rightarrow$ Kualitas Hidup & 0.4357 & -0.864 \\
\hline
\end{tabular}

Sumber: Data Primer,2017.

\section{Pengaruh Koefisien Analisis Jalur dan Kaitannya dengan Hipotesis Penelitian (Direct Effect)}

Berdasarkan koefisien jalur atau pengaruh langsung, variabel perilaku merokok berpengaruh terhadap tingkat insomnia dengan nilai koefisien sebesar 0.425 artinya bahwa jika perilaku merokok mengalami kenaikan satu poin ke arah yang lebih buruk maka tingkat insomnia akan naik sebesar 0.425 poin. Perilaku merokok berpengaruh terhadap kualitas hidup dengan nilai koefisien sebesar 0.205 artinya bahwa jika perilaku merokok mengalami kenaikan satu poin ke arah yang lebih buruk maka kualitas hidup 
akan turun sebesar 0.205 poin. Berdasarkan konsumsi kafein berpengaruh terhadap tingkat insomnia dengan nilai koefisien sebesar 0.392 artinya bahwa jika konsumsi kafein mengalami kenaikan satu poin ke arah yang lebih tinggi maka tingkat insomnia akan naik sebesar 0.392 poin. Berdasarkan konsumsi kafein berpengaruh terhadap kualitas hidup dengan nilai koefisien sebesar -0.142 artinya bahwa jika konsumsi kafein mengalami kenaikan satu poin ke arah yang lebih tinggi maka kualitas hidup akan turun sebesar 0.142 poin (Tabel 2).

Aktivitas fisik berpengaruh terhadap tingkat insomnia dengan nilai koefisien sebesar 0.192 artinya bahwa jika aktivitas fisik mengalami kenaikan satu poin ke arah yang lebih berat maka tingkat insomnia akan naik sebesar 0.192 poin. Aktivitas fisik berpengaruh terhadap kualitas hidup dengan nilai koefisien yaitu sebesar -0.369 artinya bahwa jika aktivitas fisik mengalami kenaikan satu poin ke arah yang lebih berat maka kualitas hidup akan turun sebesar 0.369 poin. Tingkat Insomnia berpengaruh terhadap kualitas hidup dengan nilai koefisien sebesar 0.409 artinya bahwa jika tingkat insomnia mengalami kenaikan satu poin ke arah yang lebih tinggi maka kualitas hidup akan turun sebesar 0.409 poin. (Tabel 2).

Tabel 2. Pengaruh Koefisien Analisis Jalur dan Kaitannya dengan Hipotesis Penelitian (Direct Effect)

\begin{tabular}{cccc}
\hline \multirow{2}{*}{ Variabel } & \multicolumn{3}{c}{ Direct Effect } \\
\cline { 2 - 4 } & Estimate & Nilai p & Kesimpulan \\
\hline Perilaku Merokok $\rightarrow$ Tingkat Insomnia & 0.425 & 0.000 & Signifikan \\
Perilaku Merokok $\rightarrow$ Kualitas Hidup & -0.205 & 0.040 & Signifikan \\
Konsumsi Kafein $\rightarrow$ Tingkat Insomnia & 0.392 & 0.000 & Signifikan \\
Konsumsi Kafein $\rightarrow$ Kualitas Hidup & -0.142 & 0.000 & Signifikan \\
Aktivitas Fisik $\rightarrow$ Tingkat Insomnia & 0.192 & 0.041 & Signifikan \\
Aktivitas Fisik $\rightarrow$ Kualitas Hidup & -0.369 & 0.000 & Signifikan \\
Tingkat Insomnia $\rightarrow$ Kualitas Hidup & -0.409 & 0.000 & Signifikan \\
\hline
\end{tabular}

Sumber: Data Primer, 2017.

Tabel 3. Pengaruh Koefisien Analisis Jalur dan Kaitannya dengan Hipotesis Penelitian (Indirect Effect)

\begin{tabular}{ccc} 
Hipotesis (Path) & $\begin{array}{c}\text { Indirect } \\
\text { Effect }\end{array}$ & $\begin{array}{c}\text { Total } \\
\text { Effect }\end{array}$ \\
\hline Perilaku Merokok $\rightarrow$ Tingkat Insomnia $\rightarrow$ Kualitas Hidup & -0.174 & -0.380 \\
Konsumsi Kafein $\rightarrow$ Tingkat Insomnia $\rightarrow$ Kualitas Hidup & -0.160 & -0.018 \\
Aktivitas Fisik $\rightarrow$ Tingkat Insomnia $\rightarrow$ Kualitas Hidup & -0.079 & -0.448 \\
\hline
\end{tabular}

Sumber: Data Primer

Pengaruh Koefisien Analisis Jalur dan Kaitannya dengan Hipotesis Penelitian (Indirect Effect)

Berdasarkan pengaruh tidak langsung antar variabel, efek tidak langsung perilaku merokok terhadap kualitas hidup melalui tingkat insomnia adalah -0.174. Hal ini dimaknai bahwa setiap peningkatan 1 poin perilaku merokok mampu menurunkan 0.174 poin kualitas hidup secara tidak langsung melalui tingkat insomnia. Efek tidak langsung konsumsi kafein terhadap kualitas hidup melalui tingkat insomnia yaitu -0.160 . Hal ini dimaknai bahwa setiap peningkatan 1 poin konsumsi kafein mampu menurunkan 0.160 poin kualitas hidup secara tidak langsung melalui tingkat insomnia. Efek tidak langsung aktivitas fisik terhadap kualitas hidup melalui tingkat insomnia adalah -0.079 .

Hal ini dimaknai bahwa setiap peningkatan poin aktivitas fisik mampu menurunkan 0.079 poin kualitas hidup secara tidak langsung melalui depresi (Tabel 3). 


\section{PEMBAHASAN}

Dari hasil penelitian ini diperoleh bahwa faktor yang mempengaruhi kualitas hidup penderita insomnia pada Mahasiswa Pasacasarjana Universitas Hasanuddin adalah perilaku merokok, konsumsi kafein, dan aktivitas fisik seseorang. Kejadian suatu penyakit sering terkait pada umur saat ditemukan daripada saat timbulnya penyakit. Angka prevalensi penyakit insomnia berdasarkan kelompok umur tidak menggambarkan risiko kelompok umur tertentu untuk terkena penyakit. Insomnia diketahui terjadi hampir pada semua usia, berkisar antara remaja sampai usia lanjut (15 tahun sampai lebih dari 70 tahun). Namun yang terbanyak adalah pada usia mudah dan produktif (Kemenkes RI, 2013). Perilaku merokok adalah suatu kegiatan atau aktivitas membakar rokok dan kemudian menghisapnya dan menghembuskannya keluar dan dapat menimbulkan asap yang dapat terhisap oleh orang-orang disekitarnya. Perilaku merokok juga dapat diartikan yaitu aktivitas menghisap atau menghirup asap rokok dengan menggunakan pipa atau rokok yang dilakukan secara menetap.

Dari hasil penelitian ini menunjukkan bahwa perilaku merokok berpengaruh terhadap tingkat insomnia karena nilai $\mathrm{p}=0.000<0.05$ dengan nilai koefisien sebesar 0.425 artinya bahwa jika perilaku merokok mengalami kenaikan satu poin ke arah yang lebih buruk maka tingkat insomnia akan naik sebesar 0.425 poin. Selain itu hasil penelitian ini menunjukkan bahwa perilaku merokok berpengaruh terhadap kualitas hidup karena nilai $\mathrm{p}=0.040<0.05$ dengan nilai koefisien sebesar -0.205 artinya bahwa jika perilaku merokok mengalami kenaikan satu poin ke arah yang lebih buruk maka kualitas hidup akan turun sebesar 0.205 poin. Berdasarkan tabel 4.10 menunjukkan efek tidak langsung perilaku merokok terhadap kualitas hidup melalui tingkat insomnia adalah -0.174 . Hal ini dimaknai bahwa setiap peningkatan 1 poin perilaku merokok mampu menurunkan 0.174 poin kualitas hidup secara tidak langsung melalui tingkat insomnia. Masalah yang timbul terkait berperilaku merokok mengalami insomnia menunjukkan bahwa perlu dilakukan pengkajian terhadap masalah tersebut, sehingga dapat dijadikan sebagai dasar penyusunan strategi pencegahan perilaku merokok dan mengalami insomnia secara efektif oleh para stakeholder (Tsutsumia dkk., 2007). Jika masalah perilaku merokok pada penderita insomnia yang telah ada selama ini masih kurang mendapatkan perhatian, maka akan semakin banyak penderita insomnia dan meningkatkan risiko perilaku merokok yang berdampak pada penurunan kualitas hidupnya. Menurut hasil penelitian Joseph dkk. (1999), perilaku merokok yang terlihat menyebabkan adanya penurunan kualitas hidup penderita insomnia.

Selain perilaku merokok, perilaku konsumsi kafein seperti kopi juga dapat menyebabkan insomnia. Sering mengkonsumsi kafein merupakan salah satu perilaku konsumsi yang berisiko. Di Indonesia berdasarkan hasil riskesdas tahun 2013 proporsi perilaku konsumsi kopi berisiko yaitu 29,3\% (Riskesdas, 2013). Penelitian Debusuk (2001) menyebutkan bahwa gaya hidup seperti mengkonsumsi kopi mengandung kafein dapat memicu jantung sehingga tubuh mendapatkan rasa segar yang dapat mengakibatkan terjadinya insomnia.

Dari hasil penelitian menunjukkan bahwa responden penderita insomnia berdasarkan variabel konsumsi kafein lebih banyak yang konsumsi lebih yaitu 196 orang $(92.1 \%)$ dibandingkan konsumsi kurang yaitu 17 orang (7.9\%). Berdasarkan tabel 4.5 menunjukkan bahwa responden penderita insomnia yang mengonsumsi kafein dengan kategori $>1$ kali/hari sebagian besar pada jenis kopi yaitu 116 orang $(54.4 \%)$ sedangkan dengan kategori 1-3 kali/minggu sebagian besar pada jenis teh yaitu 52 orang (24.4\%). Lebih dari $75 \%$ tidak pernah mengonsumsi minuman berenergi, minuman berbahan cokelat, minuman bersoda dan es krim berbahan dasar kopi, teh atau cokelat. Berdasarkan hasil uji statistik, konsumsi kafein berpengaruh terhadap tingkat insomnia 
karena nilai $\mathrm{p}=0.000<0.05$ dengan nilai koefisien sebesar 0.392 artinya bahwa jika konsumsi kafein mengalami kenaikan satu poin ke arah yang lebih tinggi maka tingkat insomnia akan naik sebesar 0.392 poin. Dari hasil temuan dilapangan, konsumsi kafein berpengaruh terhadap kualitas hidup karena nilai $p=0.00>0.05$ dengan nilai koefisien sebesar -0.142 artinya bahwa jika konsumsi kafein mengalami kenaikan satu poin ke arah yang lebih tinggi maka kualitas hidup akan turun sebesar 0.142 poin. Efek tidak langsung konsumsi kafein terhadap kualitas hidup melalui tingkat insomnia adalah -0.160. Hal ini dimaknai bahwa setiap peningkatan 1 poin konsumsi kafein mampu menurunkan 0.160 poin kualitas hidup secara tidak langsung melalui tingkat insomnia.

Aktivitas fisik yang senantiasa dilakukan secara teratur akan menyebabkan pembuluh darah cenderung lebih elastis sehingga akan mengurangi tahanan perifer, kerja jantung juga akan lebih efisien sehingga curah jantung akan berkurang dan akan menyebabkan penurunan tekanan darah yang dapat mempengaruhi kualitas tidur. Gaya hidup yang kurang menggunakan aktivitas fisik akan berpengaruh terhadap kondisi tubuh seseorang, hal ini dapat pula dipengaruhi oleh kehidupan yang semakin modern dan hidup menjadi serba mudah. Selain itu, meningkatnya kesibukan akan tugas akademik menyebabkan seseorang tidak lagi mempunyai waktu yang cukup untuk berolahraga. Aktivitas fisik secara teratur bermanfaat untuk mengatur berat badan dan menguatkan sistem jantung dan pembuluh darah.

Dari hasil penelitian menunjukkan bahwa responden penderita insomnia berdasarkan variabel aktivitas fisik lebih banyak yang memiliki aktivitas fisik buruk yaitu 123 orang $(57.3 \%)$ dibandingkan aktivitas fisik sedang yaitu 47 orang (24.6\%) dan aktivitas baik yaitu 39 orang $(18.1 \%)$. Berdasarkan hasil uji statistik diperoleh bahwa aktivitas fisik berpengaruh terhadap tingkat insomnia karena nilai $\mathrm{p}=0.041<0.05$ dengan nilai koefisien sebesar 0.192 artinya bahwa jika aktivitas fisik mengalami kenaikan satu poin ke arah yang lebih buruk maka tingkat insomnia akan naik sebesar 0.192 poin. Sejalan dengan penelitian tersebut, Rahayuningsih (2012), meneliti mengenai faktor-faktor yang mempengaruhi insomnia di Kabupaten Pekalongan, diperoleh hasil bahwa faktor aktivitas fisik merupakan salah satu faktor yang mempengaruhi penderita insomnia mengalami depresi. Temuan dilapangan juga memperlihatkan bahwa rata-rata mahasiswa telah memiliki persepsi yang positif terhadap aktivitas fisik dan manfaat beraktivitas fisik. Namun, seperti yang dikatakan oleh Nurlailah (2010), juga memperlihatkan bahwa aktivitas fisik yang berlebihan juga berbahaya bagi kesehatan sebesar 27.0\%. Meski demikian, masih banyaknya mahasiswa yang kurang mampu mengatur waktu untuk beraktivitas diakibatkan banyaknya pekerjaan yang dilakukan. Perlu dicatat bahwa aspek fisik memainkan peran penting dalam pengaturan dan kelangsungan hidup. Pada penderita insomnia, konsumsi kafein, depresi, aktivitas fisik dan sosial pengecualian mungkin berkontribusi terhadap peningkatan atau berkelanjutan kondisi reaksi penderita.

Dari hasil penelitian ini juga menunjukkan aktivitas fisik berpengaruh terhadap kualitas hidup karena nilai $\mathrm{p}=$ $0.000<0.05$ dengan nilai koefisien sebesar -0.369 artinya bahwa jika aktivitas fisik mengalami kenaikan satu poin ke arah yang lebih buruk maka kualitas hidup akan turun sebesar 0.369 poin. Hal ini didukung dengan yang ditunjukkan tabel 4.10 bahwa Efek tidak langsung aktivitas fisik terhadap kualitas hidup melalui tingkat insomnia adalah -0.079 . Hal ini dimaknai bahwa setiap peningkatan poin aktivitas fisik mampu menurunkan 0.079 poin kualitas hidup secara tidak langsung melalui tingkat insomnia.

Selain itu aktivitas fisik juga mempengaruhi self care pasien. Aktivitas fisik seseorang dapat berdampak pada kondisi psikososial seseorang yaitu depresi. Subjek penelitian cukup banyak 
mengalami depresi yang ditandai dengan perasaan bersalah ketika mereka merasa tidak dapat lagi berguna bagi banyak orang dan keluarganya sendiri. Penelitian ini sejalan dengan penelitian di Kabupaten Gowa, adanya hubungan antara kecemasan depresi dengan kejadian insomnia pada kelompok lansia yang tinggal di pati sosial Tresna Werdha Gau Mabaji Kabupaten Gowa (Zulkifli dkk., 2012)

\section{KESIMPULAN DAN SARAN}

Kesimpulan pada penelitian ini yaitu terdapat pengaruh perilaku merokok terhadap tingkat insomnia. Ada pengaruh konsumsi kafein terhadap tingkat depresi. Variabel aktivitas fisik memiliki pengaruh terhadap tingkat depresi. Ada pengaruh perilaku merokok terhadap kualitas hidup penderita insomnia. Ada pengaruh konsumsi kafein terhadap kualitas hidup penderita insomnia. Ada pengaruh aktivitas fisik terhadap kualitas hidup penderita insomnia. Ada pengaruh tidak langsung perilaku merokok terhadap kualitas hidup melalui tingkat depresi. Ada pengaruh tidak langsung konsumsi kafein terhadap kualitas hidup melalui tingkat depresi. Ada pengaruh tidak langsung aktivitas fisik terhadap kualitas hidup melalui tingkat depresi. Ada pengaruh tingkat depresi dengan kualitas hidup. Disarankan kepada Mahasiswa Pascasarjana Universitas Hasanuddin agar dapat mengurangi atau bahkan berhenti berperilaku merokok, mengontrol konsumsi kafein untuk mengkonsumsi secukupnya, dan mahasiswa berperilaku aktivitas fisik kurang dan buruk agar bisa mengubah aktivitas fisiknya menjadi aktivitas fisik yang baik.

\section{DAFTAR PUSTAKA}

Annahri, dkk. (2013). Hubungan antara Perilaku Merokok dengan Angka Kejadian Insomnia pada Mahasiswa Fakultas Kedokteran Universitas Lambung Mangkurat. Jurnal Psikologi. Banjarmasin: Universitas Lambung Mangkurat.

Bakrie, I. (2010). Penderita Insomnia. Available: http://www.tnol.co.id/bugar/1485-

memberikan-

semangathidupmerupakan-obatmujarab-penderita-insomnia.html

Bello, A. I., Dengzee, S. A. \& Iyor, F. T. (2013). Health Related Quality of Life Amongst People Affected by Insomniac in South Ghana: A Needs Assessment. Quality of Life in Patients with Insomniac. Available:

https://www.insomniac.org.uk/platf orms/insom/files/lr/Apr13/IS_Apr13 1741. pdf.

Brook, David W., M.D Elizabeth, Rubenstone B.A., Chenshu Zhang, Ph.D. (2012). Cognitive behavioral therapy to prevent chronification of insomnia. EPMA Journal, 2(1): 309314.

Brouwers. (2011). Quality of Life, Perceived Stigme South-Easth Nepal. 2011. Available:dcidj.org > ... > Vol 22, No 1.

Cantero, Potter \& Leach. (2007). Perceptions of Quality of Life, Sense of Community and Life Satisfaction among Erderly Resident in Schuyler and Crete, Nebraska, Faculty Scholarly and Creative Activity.

Chingu, D., Duncan, M. \& Amosun, S. (2013). The Quality of Life of People with Insomniac-Related Residual Impairment- Is There a Difference between People Living in a Insomniac and Those ReIntegrated into Their Communities? The quality of life of people with insomniac-related residual impairment. Available: http://www.insomniac.org.uk/platfor ms/insom/files/lr/Dec13/ins292301.pdf.

Depkes RI. (2005). Pendekatan Dan Penanganan Pada Remaja Beresiko Tinggi. Available at: http://www.dinkes.bwi.net/pkjm/htm $1 /$ modules.php?Op=modload\&name $=$ News\&file+article\&sid.

Fatayi. (2008). Penilaian Kualitas Hidup Penderita Insomnia Berdasarkan 
Aspek Kesehatan Fisik dan Mental (Tesis). Jakarta: Fakultas Kedokteran Universitas Indonesia.

Gaung. (2009). The Effect physical activity on depression with insomnia. Insomnia Journal, 44(18).

Heikkinen, H. (2010). Smoker's Account On The Health Risk Of Smoking: Why Is Smoking Not Dangerous For Me? Available: Error! Hyperlink reference not valid.

Japardi, I. (2002). Gangguan Tidur. Sumatera Utara: Fakultas Kedokteran Bagian Bedah Universitas Sumatera Utara.

Joseph, G. A. \& Rao, P. S. (1999). Impact of Insomniac on the Quality of Life. Bull World Health Organisation. Available: https://www.ncbi.nlm.nih.gov/pmc/a rticles/ PMC2557686/.

Kaplan, H. I., Sadock, B. J. \& Grebb, J. A. (1997). Sinopsis Psikiatri Jilid I. Jakarta: Binarupa Aksara.

Kemenkes RI. Riset Kesehatan Dasar. (2013). Jakarta: Kementerian Kesehatan Republik Indonesia.

Kumboyono. (2011). Analisis Faktor Penghambat Motivasi Berhenti Merokok Berdasarkan Health Beliefe Model pada Mahasiswa Fakultas Teknik Universitas Brawijaya Malang. Jurnal Keperawatan Soedirman (The Soedirman Journal of Nursing);6(1).

Kuniarto. (2006). Penderita Insomnia. Kompas, Maret 23; Opini hal. 6.

Kusuma, H. (2011). Hubungan Antar Depresi Dengan Dukungan Keluarga Dengan Kualitas Hidup Penderita Insomnia Yang Menjalani Rawat Jalan Di Rspun Cipto Mangkusumo Jakarta (Tesis). Jakarta: Universitas Indonesia.

LeBourgeois, MK., Giannotti, F., Cortesi, F., Wolfson, AR., \& Harsh, J. (2005). The relationship between reported sleep quality and sleep hygiene in Italian and American adolescents. Pediatrics, 115:257-65.

MD, D. G. \& MD, B. A. B. (2014). Hiv Dan Psikiatri. Jakarta: Spiritia.
Available:

http://www.spiritia.or.id/cst/dok/kesji wa2.pdf [

Nurlailah, N. (2010). Hubungan antara persepsi tentang dampak merokok terhadap kesehatan dengan tipe perilaku merokok mahasiswa Universitas Islam Negeri Syarif Hidayatullah Jakarta.Skripsi. Jakarta: Fakultas Psikologi UIN.

Rafknowledge. (2004). Insomnia dan Gangguan Tidur Lainnya. Jakarta: Gramedia.

Rahayuningsih, E. (2012). Analisis Kualitas Hidup Penderita Insomnia Di Kedaung Wetan Kota Tangerang Tahun 2012. Available: lib.ui.ac.id/file?file= digital $/ 2031518$ 8-T31918-Analisis\%20kualitas.pdf.

Romauli. (2014). Pengaruh Gaya Hidup Terhadap Kejadian Hipertensi Di Rsud Dr. H. Kumpulan Pane Tebing Tinggi Tahun 2014 (Tesis). Medan: Universitas Sumatera Utara.

SIbagariang, R. (2007). Stigma Masyarakat Terhadap Penderita Insomnia. Universitas Indonesia.

Potter, P. A., \& Perry, A. G. (2005). Buku ajar fundamental keperawatan: konsep proses dan praktik. Jakarta: EGC.

Tsutsumia, A., Izutsub, T., Islamc, A. M., Maksudad, A. N., Katoa, H. \& Wakaie, S. (2007). The Quality of Life, Mental Health, and Perceived Stigma of Insomniac in Bangladesh. Social Science and Medicine. Available:

http://www.sciencedirect.com/scienc e/article/ pii/S0277953607000585.

V, P. R., IR, R. \& DD, P. (2000). SocioEconomic Rehabilitation Programme of Insomniac India Methodology, Results and Application of Needs-Based SocioEconomic Evaluation. Insomniac Rev, 71.

Yocki. (2007). Faktor-Faktor Penyebab Insomnia Pada Mahasiswa (Tesis). Semarang: Fakultas Psikologi Universitas Katolok Soegijapranata. 
Zeidler, M. R. Insomnia. (2011).

Available:

http://www.emedicina.medscape.co m/article/ 1187829.com

Zulkifli, A., Arsunan, A., Yahya, M. (2012). Determinan Insomnia pada Usia Lanjut. Jurnal Kesehatan Masyarakat Nasional. Makassar: Universitas Hasanuddin ;7(4). 